\title{
Chapter 3 \\ Model Coupling Approach \\ for the Analysis of the Future European \\ Energy System
}

\author{
Robert Kunze and Steffi Schreiber
}

\begin{abstract}
In REFLEX ten different bottom-up simulation tools, fundamental energy system models, and approaches for life cycle assessment are coupled to a comprehensive Energy Models System. This Energy Models System allows an in-depth analysis and simultaneously a holistic evaluation of the development toward a lowcarbon European energy system with focus on flexibility options up to the year 2050. Different variables are exchanged among the individual models within the Energy Models System. For a consistent analysis, relevant framework and scenario data need to be harmonized between the models.
\end{abstract}

\subsection{Introduction}

Model-based energy system analyses have been used successfully for many decades to evaluate and forecast the influences of political and techno-economic framework conditions on system development (e.g., EC 2016, 2018; Keramidas et al. 2020). While the initial focus of model development was primarily on the creation of analysis tools with a total system view, the latest change in the energy landscape and the associated enormous variety of new aspects and options for system design in recent years has led to the development of a broad spectrum of models, each with a specific analysis focus. The main reason for this is that the complexity of new trends in the areas of energy supply and use (e.g., decentralization and sector coupling as well as new actors, technologies, and possibilities for energy source change) cannot be taken into account with the required level of detail within a single model approach. However, the comprehensive and cross-sectoral system view still plays an important role, as there are numerous interdependencies along the entire energy value chain. Thus, the coupling of total and detailed partial models to a consistent Energy

R. Kunze $(\bowtie)$

Energy Systems Analysis Associates - ESA ${ }^{2} \mathrm{GmbH}$, Dresden, Germany

e-mail: Robert.Kunze@esa2.eu

S. Schreiber

Chair of Energy Economics, Technische Universität Dresden, Dresden, Germany

(C) The Author(s) 2021

D. Möst et al. (eds.), The Future European Energy System,

https://doi.org/10.1007/978-3-030-60914-6_3 
Models System (EMS) is the decisive key to consider the interactions of relevant techno-economic options in the development of sustainable energy supply strategies adequately.

The core objective of REFLEX is to analyze and evaluate the development toward a low-carbon energy system with focus on needed flexibility options in Europe. In order to answer the research questions of the project, an interdisciplinary approach is chosen by combining analytical methods and tools from the research fields of techno-economic learning, energy system modeling as well as environmental and social life cycle assessment (LCA).

To link and apply the specific approaches of these three research fields in a compatible way, an innovative Energy Models System was developed. This Energy Models System comprises ten individual models that were originally developed as standalone applications by different institutions. The model pool in REFLEX contains bottom-up simulation tools and fundamental energy system models on national and European level as well as approaches for environmental and social life cycle assessment (eLCA, sLCA). These models are coupled based on a common database that contains the harmonized scenario and framework data for all models and serves at the same time for the exchange of intermediate results between the models. ${ }^{1}$

The data-side coupling of independently developed model approaches poses a number of challenges with regard to different levels of aggregation (spatial, sectoral, technological, etc.) and time related structures (yearly, hourly, etc.) of the needed input data and provided result data. Furthermore, the models use different identifier structures and labels as well as varying file formats. In order to manage those challenges and to enable a smooth data exchange between the models, a special interface tool for the common database was developed. The interface is adapted to the specific data needs of each model and allows a comprehensive mapping of data sets. This ensures that each model can read its result data into the database without reformatting, and each model that reuses this data receives it directly in the required structure and format.

\subsection{Description of Applied Models}

This section gives a brief overview of the models applied in REFLEX and their specific focus. The models can be grouped into three fields (cf. Fig. 3.1): (i) energy supply and markets, (ii) energy demand and (iii) impacts on the environment and society. The EMS covers the electricity, heat, and hydrogen supply sectors as well as all sectors on the demand side (industry, tertiary, residential, and transport sector). The interlinkage of the models allows an adequate consideration of interdependencies between all sectors such as interrelations between energy prices and demand.

\footnotetext{
${ }^{1}$ Most of the input and result data are open access available via following data platform: https:// data.esa2.eu/tree/REFLEX.
} 


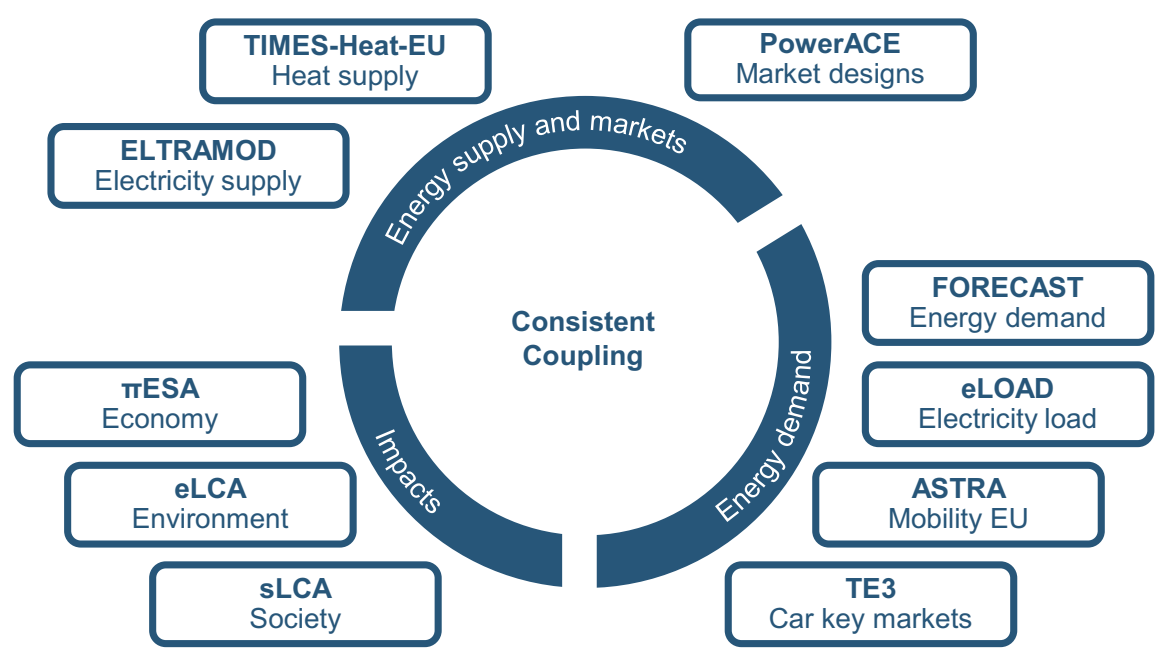

Fig. 3.1 Schematic categorization of applied models in the REFLEX Energy Models System (Source Own illustration)

- ELTRAMOD analyzes the development and operation of electricity generation capacities, storage facilities, and further flexibility options in the European electricity system.

- TIMES-Heat-EU is applied for modeling the heat supply sector by heat-only as well as combined heat and power (CHP) plants.

- PowerACE analyzes the impact of different electricity market designs (energyonly market and capacity market) on investments in flexibility options and their contribution to the security of supply at national and European level.

- FORECAST provides EU-wide projections of the future energy demand in the industry, tertiary and residential sector, considering different types of demand related policies.

- $\boldsymbol{e} \boldsymbol{L O A D}$ transforms yearly electricity demand into hourly load curves, considering demand side management.

- ASTRA simulates the transport system development as well as the resulting energy demand in the European transport sector considering all modes of transport.

- $\mathbf{T E 3}$ focuses on the road passenger transport with focus on the development of various driving technologies in global key markets.

- $\boldsymbol{e} \boldsymbol{L C A}$ and $\boldsymbol{s} \boldsymbol{L C A}$ assess impacts of the energy systems on environment and society.

- $\boldsymbol{\pi} \boldsymbol{E S A}$ calculates changes of environmental states with respect to air quality and human health.

Essential aspects of the individual models are briefly presented in the following. 


\subsubsection{ELTRAMOD}

\section{(by Technische Universität Dresden)}

\subsubsection{General Information}

ELTRAMOD (Electricity Transshipment Model) is a fundamental, deterministic and linear optimization model, which is implemented in GAMS ${ }^{2}$. It calculates the costminimal investments and dispatch in additional power plant capacities, storage facilities and power-to-X-technologies (i.e., power-to-heat, power-to-gas) in the European electricity market by assuming full competition and perfect foresight (Schreiber et al. 2020; Zöphel et al. 2019; Ladwig 2018; Schubert 2016). The model includes the EU-27 member states plus United Kingdom, Norway, Switzerland, and the Balkan countries. Electricity trading between market areas is determined endogenously by the model and limited by net transport capacities (NTC) while the electricity grid within one country is neglected. Each country is treated as one node with country specific hourly time series of electricity and heat demand as well as renewable feedin. Within ELTRAMOD all relevant policies concerning the European electricity market are implemented, such as the feed-in priority of renewable energies in each country with the respective regulatory framework. To ensure priority feed-in, curtailment is possible without penalty payments. The EU emission trading system (ETS) is modeled implicitly by considering prices for $\mathrm{CO}_{2}$ emission allowances. Within the REFLEX project ELTRAMOD is used to analyze the penetration of different flexibility options and their contribution to RES integration as well as the interdependencies among various flexibility options in the European electricity system, taking existing regulatory frameworks into account. Furthermore, crucial flexibility measures for achieving the transformation toward a low-carbon electricity system and supporting policy recommendations are identified.

\subsubsection{Model Structure}

The target function of the linear optimization problem is the minimization of the total system costs, which is the sum of the operational costs, the load change costs for ramping up and down, annualized capacity specific overnight investment costs for additional conventional power plants, storages, and power-to-X-technologies. Due to the size of the optimization problem the model is divided in an investment and a dispatch model. The investment model uses a reduced time frame based on represented weeks selected by a hierarchical cluster algorithm. The results of the investment model are fixed and serve as input for the dispatch model with hourly time resolution ( $8760 \mathrm{~h} / \mathrm{a})$. The main restriction of ELTRAMOD is the energy balance.

\footnotetext{
${ }^{2}$ The model code is written in GAMS $®$ language (General Algebraic Modeling System). A CPLEX solver with a barrier algorithm (interior-point method) is used.
} 
For each time step and country this constraint in general ensures that the electricity generation per technology has to be equal to the residual load. Additionally, the curtailed intermittent RES, exported and imported electricity, storage (dis-)charging as well as load increase due to power-to-X-technologies (i.e., power-to-heat, powerto-gas) are part of the energy balance. The investments in new capacities are restricted for some technologies according to national legislation. Due to geographical limitations, it is assumed that the potential of conventional hydro power plants (pumped storage plants, reservoirs) is exhausted. Also, the expansion of nuclear, lignite, and coal power plants is limited based on national policy targets of each country. Further, additional investments in less efficient power plants as plants with gas or oil steam turbines (GasSteam, OilSteam) as well as plants with open cycle gas or oil turbines (OCGT, OCOT) are restricted to the must-run requirements of CHP plants. As part of the model coupling some fuel specific technologies are implemented with exogenous minimal investment restrictions in ELTRAMOD to include results by TIMES-Heat-EU regarding CHP capacities. Furthermore, other technical constraints limit the generation of conventional power plants to the installed capacity and the technology-specific availability. The hourly electricity exchange flows are restricted with the available NTC. Pump storage plants, adiabatic compressed air energy storages and lithium-ion as well as redox-flow-batteries represent the electricity storages within the model. To display the flexibility of storages accurately, both the charge and discharge process as well as the available storage capacity are modeled. Load increasing power-to-heat technologies are dependent on the country specific yearly heat demand and normalized hourly heat profiles. As benchmark technology from the heat sector gas boilers can also cover the heat demand. Power-to-gas applications need to satisfy the yearly hydrogen demand derived from ASTRA based on fuel cell development pathways for the transport sector. Additionally, the yearly hydrogen demand from the industry sector, which results from FORECAST, needs to be covered by further capacity expansion of electrolyzers.

\subsubsection{TIMES-Heat-EU}

(by AGH University of Science and Technology Kraków)

\subsubsection{General Information}

TIMES-Heat-EU is a bottom-up, linear optimization model built with the use of TIMES generator (Loulou 2008). It belongs to the class of integrated capacity expansion and dispatch planning models.

The objective function maximizes the total surplus of district heat producers. Supply technologies incorporated into the model consist of: (i) combined heat and power plants (CHP), (ii) heat only plants (HOP), (iii) power-to-heat plants (PtH), and (iv) thermal energy storages (TES). The geographical coverage of the model extends 
over the EU-27 member states plus United Kingdom. Each country considers its own district heat systems with no trade between countries. The modeling time horizon covers the period from 2015 to 2050 with 5 years' time steps. Each modeling year is further divided into 224 time-slices derived by aggregating the data every three hours in seven days for four seasons $(8 \times 7 \times 4)$. The annual district heat demand, which is the exogenous parameter into TIMES-Heat-EU model derived from the FORECAST model, is split into three categories depending on the end-use sector i.e., residential, tertiary or industry. For the first two sectors the annual demand is split into individual time-slices mainly taking into account the variations of the outdoor temperature, whereas for industry it is split rather evenly.

TIMES-Heat-EU considers major EU policies related to district heating (e.g., requirements for high efficiency cogeneration). Some more detailed operational constraints (power-to-heat ratios or ramp rates) were also defined. The EU emission trading system (ETS) is modeled implicitly with the help of $\mathrm{CO}_{2}$ allowance prices and emission factors for individual fuels.

Within the REFLEX project the TIMES-Heat-EU model assesses the transition pathways towards more sustainable district heat supply and analyzes the role of district heating (DH) systems in enhancing energy system flexibility.

\subsubsection{Model Structure}

TIMES-Heat-EU solves the linear programing problem of district heat supply. The optimization is constrained by a set of equation and inequalities, which include (i) commodity balance equations for district heat, electricity, fuels and emissions, (ii) annual overall efficiency requirements for CHPs in compliance with the EU legislation, (iii) required share of electricity generated in highly efficient cogeneration, and (iv) ramping constraints for the operation of units. The model is optimizing the entire modeling time period with perfect knowledge of the conditions in each time-slice (i.e., perfect foresight approach). The model runs iteratively. Each new iteration step is running with an updated district heat price that is calculated based on the results of the previous run as weighted average production costs plus margin. CHP plants sell the electricity at the wholesale prices determined by ELTRAMOD.

Inelastic demands are assumed in each modeling time-slice. These DH demands must be satisfied by $\mathrm{DH}$ generators, $\mathrm{PtH}$ and outflows from the thermal energy storages (TES). Heat storage technologies are divided into two groups: (i) short time storages, operating on daily basis, with storage capacity up to one week, and (ii) interseasonal storages, operating on seasonal level. All TES technologies are modeled as three step processes, i.e., with input and output processes, in which capacity is represented by the unit of power as well as the storage process, in which the capacity is represented by the unit of energy. $\mathrm{PtH}$ technologies, which are represented by electric boilers and heat pumps, can use the electricity that would be otherwise curtailed (free of charge) or simply buy electricity by paying the electricity wholesale price.

The CHP plant operation is therefore driven by three main factors: (i) district heat prices, (ii) wholesale electricity prices and (iii) turbine specified technological 
restrictions. Moreover, the required quota of electricity from CHPs is specified, e.g., in the Mod-RES and High-RES centralized scenario it is required that $12 \%$ of total electricity produced is provided by CHPs.

\subsubsection{PowerACE}

(by Karlsruhe Institute of Technology $)^{3}$

\subsubsection{General Information}

PowerACE is an agent-based simulation model developed for the analysis of European electricity markets in long-term scenario analyses. The model runs at hourly resolution ( $8760 \mathrm{~h} / \mathrm{a})$ over a typical time horizon from 2015 up to 2050 . PowerACE covers different market segments with a focus on the day-ahead market and different types of capacity remuneration mechanisms. Various agents represent the associated market participants, such as utility companies, regulators, and consumers. The electricity suppliers can decide on the daily scheduling of their conventional power plants and storage units as well as on the construction of new conventional generation or storage capacities. Thus, the short-term and long-term decision levels are jointly considered and their interactions can be investigated. Ultimately, the development of the markets emerges from the simulated behavior of all agents.

\subsubsection{Model Structure}

PowerACE is structured into different market areas, in each of which multiple traders are active on the day-ahead market. All agents participating in the market first create a price forecast and then prepare hourly demand and supply bids. The bid prices for the supply bids are primarily based on the variable costs of the respective power plant. In addition, the price forecast is used to estimate the running hours of each power plant and to distribute the expected start-up costs accordingly. Further, price-inelastic bids for demand, renewable feed-in and storage units are prepared by a single trader per market area, respectively. Once all bids have been prepared, they are submitted to the central market coupling operator. In the market clearing process, supply and demand bids are matched across all market areas, such that welfare is maximized subject to the limited interconnector capacities between the different market areas. For a formal description and details of the market coupling and clearing see Ringler et al. (2017). As a result, the information about which bids have been partly or fully accepted is returned to the different traders. Final outcome of the day-ahead market

\footnotetext{
${ }^{3}$ This model description is based on Fraunholz and Keles (2019).
} 
simulation is a market clearing price and corresponding electricity volume for each simulation hour and market area.

In addition to the short-term decisions on the day-ahead market, the different utility companies modeled as agents in PowerACE can also perform long-term decisions on investments in new flexible power plant and storage capacities at the end of each simulation year. Contrary to the common approach of generation expansion planning with the objective of minimizing total future system costs, again an actor's perspective is taken. Consequently, investments are only carried out if expected to be profitable by the investors according to their respective annuities. The decisions of the different investors are primarily based on their expectations regarding future electricity prices. As these, vice versa, are influenced by the investment decisions of all investors in all interconnected market areas, a complex game with multiple possible strategies opens up. To find a stable outcome for this game, a Nash-equilibrium with the different market areas as players needs to be determined. Therefore, the expansion planning algorithm terminates when all planned investments are profitable and at the same time none of the investors is able to improve his expected payoff by carrying out further investments, i.e., there is no incentive for any investor to unilaterally deviate from the equilibrium outcome. More details on the expansion planning algorithm are described in Fraunholz et al. (2019).

For the application of PowerACE within REFLEX, the representation of different capacity remuneration mechanisms (central buyer mechanism and strategic reserve) is an essential element. A detailed description of the modeled mechanisms is provided in Keles et al. (2016).

In the market areas with an active central buyer mechanism, annual descending clock auctions are carried out in order to contract a specific amount of secured generation and storage capacity. The regulator first sets a reserve margin, which is calculated as the ratio between secured capacity and maximum peak residual demand in the respective year, excluding imports. Next, the different utility companies provide capacity bids consisting of volume and price. Existing capacity and investments expected to be profitable even without additional capacity payments bid into the auction at zero cost. The bid price for additional investments is determined based on the additional income that would be needed to recover all cost related to the respective investment, the so-called difference costs. Finally, the auction is cleared and all successful participants are compensated with a uniform capacity price.

If active in the respective market area, the strategic reserve is contracted once every simulation year via a uniform price auction. The regulator sets a specific capacity target to be procured and the different utility companies can then offer their conventional generation capacities. Once part of the strategic reserve, a power plant is no longer allowed to participate in any other market. For this reason, earnings from the strategic reserve have to cover all yearly costs of a given power plant, namely fixed costs for operation and maintenance as well as opportunity costs for lost income from e.g., the day-ahead market. The contracted power plants are then only being used by the regulator as a last resort in extreme scarcity situations. 


\title{
3.2.4 FORECAST
}

\author{
(by Fraunhofer ISI and TEP Energy $\mathrm{GmbH})^{4}$
}

\subsubsection{General Information}

The FORECAST modeling platform aims to develop annual long-term scenarios for the sector-specific simulation of annual final energy demand of individual countries and world regions until 2050. The modeling is based on a bottom-up approach considering characteristics of individual demand sectors, dynamics of technologies and socio-economic drivers. The model allows to address research questions related to energy demand including scenarios for the future demand of individual energy carriers like electricity or natural gas, calculating energy saving potentials and the impact on greenhouse gas emissions as well as abatement cost curves and ex-ante policy impact assessments.

\subsubsection{Model Structure}

FORECAST comprises four individual modules, each representing one sector with high resolution according to the Eurostat (or national) energy balances: the industrial, tertiary and residential sector as well as the module "other sectors" including the agriculture and transport sector in a more aggregated form (Fleiter et al. 2018; Elsland 2016; Jakob et al. 2012; cf. Fig. 3.2). While all sector modules follow a similar bottom-up methodology, they also consider the particularities of each sector like technology structure, heterogeneity of actors and data availability.

In Fig. 3.2 a schematic overview of the FORECAST model structure is illustrated. Next to the scenario definition data (e.g., gross domestic product or policy intensity), the FORECAST platform contains a macro module that determines the activity variables for the individual modules and sectors (e.g., gross value added by industrial sub-sectors and past trends). A second module forecasts sectoral retail prices by considering production or trade prices and various tax and fee components. Each of the four sector modules is divided into three hierarchical levels, i.e., the industrial sector is clustered in (i) industrial sub-sectors (branches) (ii) differentiated according to sector-specific processes and (iii) process- or technology-specific savings options, for instance.

The main advantage of the bottom-up simulation model FORECAST is its high degree of technological detail. Each sector requires sector-specific activity data, like industrial production in the industry sector and the number of households in the residential sector. Furthermore, end-consumer energy prices play an important role in each sector as they are distinguished by energy carrier. The third group of input data, the technology characterization also reflects data availability of the individual sectors.

\footnotetext{
${ }^{4}$ The model description is based on Fraunhofer ISI et al. (2017).
} 


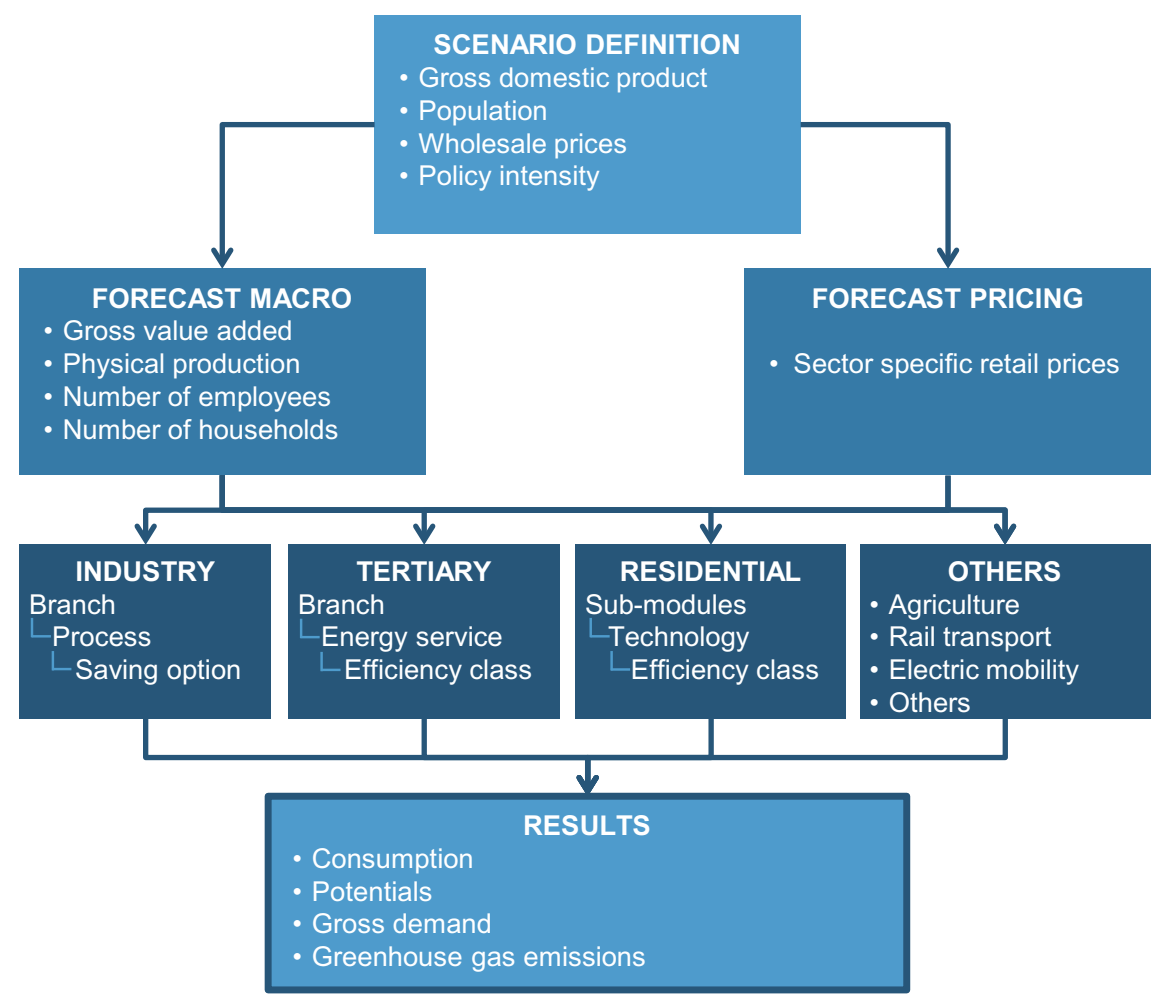

Fig. 3.2 Schematic overview of FORECAST model structure. Figure adapted and based on Fraunhofer ISI et al. (2017)

While in the industry and tertiary sector the model works with so-called energyefficiency measures (EEMs), which represent all kinds of actions that reduce specific energy consumption, in the residential sector the stock of alternative appliances and the market share of different efficiency classes are explicitly modeled. In all cases, energy savings can be calculated and traced back to technological dynamics including cost considerations. As a result of the bottom-up approach model results can be disaggregated with a very high resolution comprising sectors and sub-sectors, but also end-uses technologies and energy carriers.

In addition to the national analysis, the FORECAST platform also includes a module for regional analysis of electricity demand. The regional module uses technology- and sector-specific distribution keys to calculate a spatially resolved demand differentiated by NUTS3 regions (administrative districts and independent cities). This is based on extensive data analyses of structural data, including the spatial distribution of population, households, employees, industrial locations, and weather data.

In REFLEX, the FORECAST model is primarily responsible to provide projections for the future energy demand, considering different types of demand related 
policies. The demand projections cover different energy carriers and are available on an annual basis. The yearly electricity demand is further transformed into hourly load curves by the eLOAD model.

\subsection{5 eLOAD}

(by Fraunhofer ISI) $)^{5}$

\subsubsection{General Information}

The eLOAD (electricity LOad curve ADjustment) model has been developed to project future electricity load curves on a national level based on application specific hourly load profiles. The model assesses the transformation of the load curve due to structural and technological changes on the demand side. This also includes demand response (DR) measures through the flexible use of new technologies, which can lead to a smoothing of the residual load. For this purpose, cost-optimal load shifting activities of suitable appliances such as cooling devices or electric vehicles are determined based on a mixed-integer optimization for the demand side. The results of eLOAD can provide information on future peak loads and load ramp rates, which are important parameters for investment decisions regarding the development of needed generation capacities and grid infrastructure.

\subsubsection{Model Structure}

The deformation of the load curve due to structural changes and the integration of new technologies on the demand side is modeled with the first module of eLOAD. In this module, the method of partial decomposition is used. The method applies a database with more than 600 technology-specific load profiles from field studies, building simulations and industrial projects, to cope with the great variety of individual load structures on the demand side. With the additional consideration of weather data, the partial approach thus allows a transformation of the historical load curve profile in dependence of future changing electricity applications while characteristic irregularities and stochastic outliers from the historical load curves are preserved.

The role of eLOAD in REFLEX is twofold. First, eLOAD translates the annual electricity and heat demand projections delivered by the FORECAST model into hourly load curves. While electricity load curves serve as an input for the electricity market models ELTRAMOD and PowerACE, the heat load curves are transferred to the TIMES-Heat-EU model.

\footnotetext{
${ }^{5}$ The model description is based on Gnann et al. (2018).
} 
Second, eLOAD is required to estimate technology distinct demand response potentials. These potentials are characterized by seasonal, weekly, and daily variations and depend on the dynamic tariff mechanism considered. The eLOAD results allow to draw conclusions on the potential contribution of demand response for peak load shaving and the integration of renewable energy sources and on the extent to which the potential is affected by energy-efficiency policies. In addition, the demand response potentials are used in the ELTRAMOD model in the framework of a system optimization approach that determines the cost-optimal mix of flexibility options to ensure a stable European electricity supply system.

\subsubsection{ASTRA}

(by Transporti e Territorio and Fraunhofer ISI)

\subsubsection{General Information}

ASTRA (ASsessment of TRAnsport Strategies) is an integrated assessment model that simulates the transport system development in combination with the economy and environmental impacts until the year 2050. The model is based on the System Dynamics approach and built in Vensim ${ }^{\circledR}$. Geographically, ASTRA covers all EU-27 member states plus Norway, Switzerland, and the United Kingdom.

A strong feature of ASTRA is the ability to simulate and test integrated policy packages and to provide indicators for the indirect effects of transport on the economic system (e.g., GDP growth, employment). Strategic assessment capabilities in ASTRA cover a wide range of transport measures and investments with flexible timing and levels of implementation. Potential policies include vehicle technologies, infrastructure development, pricing, taxation, speed limits, and trade policies etc. The model produces outcomes for diverse impact types; in particular transport system operation, economic, environmental, and social indicators. ASTRA has been successfully applied for transport, renewable energy, and climate policy assessments as well as for technology and scenario analysis. For such analyses the ASTRA model has often been coupled to bottom-up techno-economic models. The model has been applied for national as well as EU-wide studies addressing the following topics:

- Transport policy assessment: pricing, taxation (on fuel or vehicle), emissions and efficiency standards, infrastructure investments

- Technology and scenario analysis: alternative vehicle technology (e.g., electric and fuel cell vehicles), integrated energy and transport policy (e.g., vehicle efficiency improvement)

- Renewable policy assessment: subsidies, feed-in tariffs, investment strategies

- Climate policy assessment: and energy price trends 


\subsubsection{Model Structure}

As illustrated in Fig. 3.3, ASTRA consists of six different modules, each related to one specific aspect such as the economy, transport demand, or the vehicle fleet. These modules are linked and interact with each other via direct effects and feedback mechanisms. The main modules cover the following aspects:

- Population and social structure (age cohorts and income groups)

- Economy (input-output tables, employment, consumption, and investment)

- Foreign trade (inside EU and to partners from outside EU)

- Transport (demand estimation, modal split, transport cost, and infrastructure networks)

- Vehicle fleet (passenger and freight road vehicles)

- Environment (pollutant emissions, $\mathrm{CO}_{2}$ emissions, and fuel consumption).

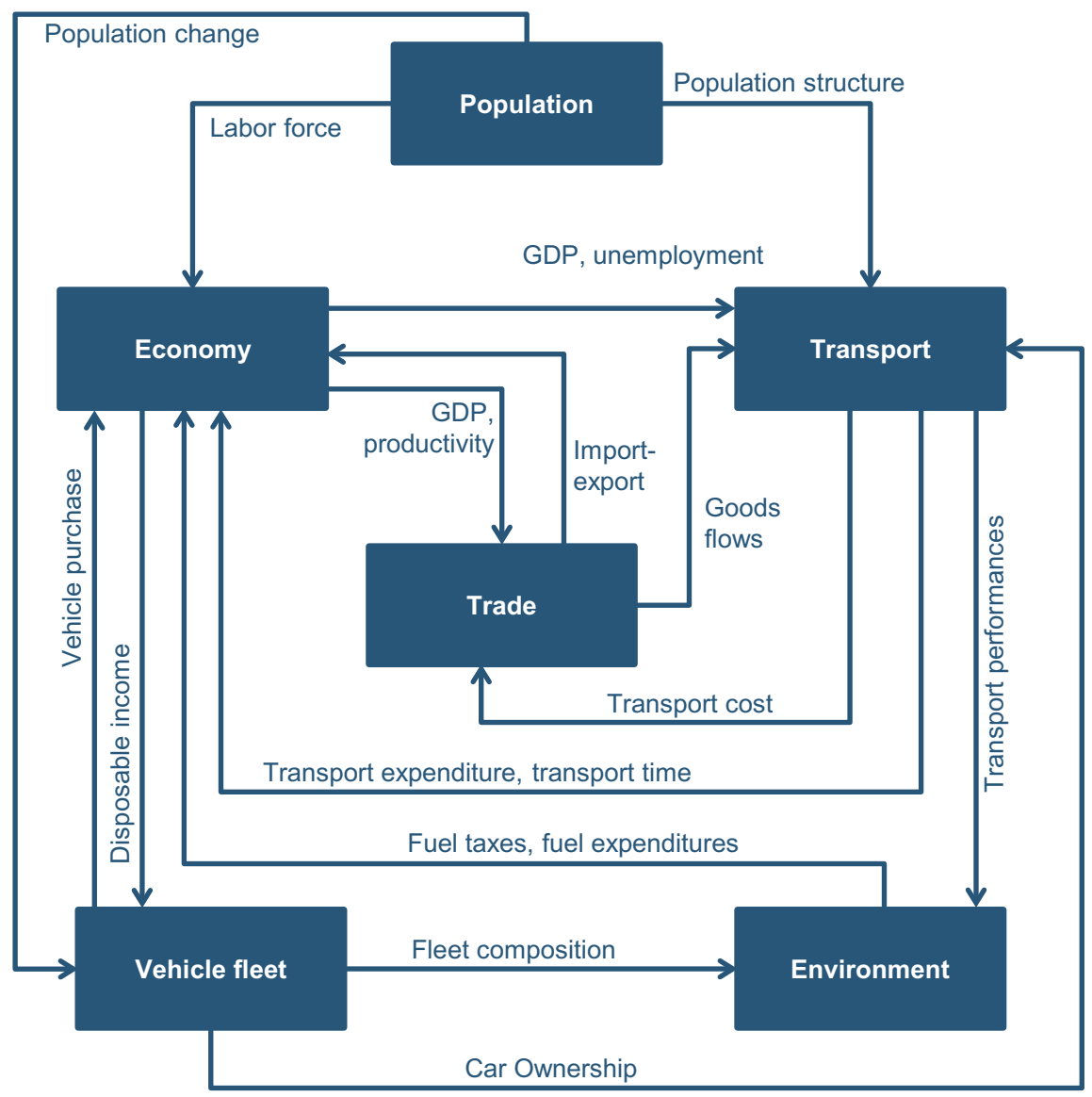

Fig. 3.3 The ASTRA model structure (Source Own illustration) 
The economy module simulates the fundamental economic variables. Some of these variables (e.g., GDP) are transferred to the transport generation module, which uses the input to generate a distributed transport demand. In the transport module, demand is split by mode of transport and traffic performance is calculated. The environment module uses inputs from the transport module (in terms of vehiclekilometers-traveled per mode and geographical context) and from the vehicle fleet module (in terms of the technical composition of vehicle fleets), in order to compute energy consumption, greenhouse gas, and air pollutant emissions.

To analyze sustainable transition scenarios, the model was enhanced by alternative drive technologies for vehicle fleets, new mobility concepts and behavioral change options toward active modes (Martino et al. 2018, 2019).

The diffusion of alternative drive technologies for road vehicles is simulated in the vehicle fleet module based on an adapted Total Cost of Ownership (TCO) approach separately for different vehicle categories. These categories comprise private and commercial cars, light duty vehicles, and heavy duty vehicles in four gross vehicle weight categories, urban buses, and coaches. Based on the technical characteristics of available fuel options today and in the future and the heterogeneous requirements of the different users, a set of fuel options is available for each vehicle category. Technologies cover gasoline, diesel, liquefied petroleum gas, compressed, and liquefied natural gas (LNG), battery electric vehicles, plug-in hybrid electric vehicles, fuel cell electric vehicles, and trolleys for urban buses and long-distance trucks. Nonroad vehicle fleets like inland waterways, maritime ships, air planes, and railways are modeled in less detail due to a lack of detailed statistics, long average lifetimes, and only few renewable fuel options imaginable for the time horizon until 2050. As alternative fuel options, ASTRA considers blended kerosene with biofuels for planes, an increasing share of electrified traction for railways, and biodiesel and LNG for maritime ships and inland waterways.

As the number of car-sharing users grew rapidly in many EU member states and active modes are becoming more popular in several cities, specific algorithms were implemented to simulate the diffusion of car-sharing mobility services and their impacts on mobility indicators; furthermore, the active passenger transport modes walking and cycling were explicitly considered for urban areas.

In REFLEX, ASTRA is coupled with the models FORECAST, eLOAD, and ELTRAMOD to simulate feedback mechanisms between electricity consumption patterns and prices and with the TE3 model to consider global learning effects for electric vehicle diffusion.

\subsubsection{TE3}

(by Karlsruhe Institute of Technology) 


\subsubsection{General Information}

TE3 (Transport, Energy, Economics, Environment) is a multi-country computer simulation model capable of generating scenarios and suitable for policy analysis. The TE3 model is a simplified representation of the road passenger transport system, with focus on car travel activity and car powertrain technologies. Given the complexity and uncertainty of the system under study, systems thinking and scenarios analysis are adopted as a guiding research principle and methodology, respectively. The TE3 model has been developed by applying the System Dynamics (SD) approach and is implemented in the Vensim ${ }^{\circledR}$ platform. The methodology is mixed, as the model contains elements of other methods. In particular, the modeling exercise underlying TE3 can be divided into three main steps:

1. Projection of the total car stock by means of an aggregate econometric model;

2. Simulation of market shares by car technology by means of a discrete choice modeling framework; and

3. Estimation of energy use and greenhouse gas emissions by means of an accounting framework.

\subsubsection{Model Structure}

The TE3 model illustrates future development pathways for car technologies (nine powertrains) and offers an international perspective by covering six main car markets (China, France, Germany, India, Japan, US). In REFLEX the TE3 focus is on four non-European markets. The time horizon is limited to the period from 2000 to 2050 . The model accomplishes its objective by creating scenarios of the dynamic market penetration of alternative car technologies, considering direct and indirect emissions, and incorporating a set of policy measures. TE3 can be regarded as a hybrid model, as it follows an approach that contains top-down and bottom-up features. Core to the TE3 model is the representation of feedback loops. A modular approach, which is illustrated in Fig. 3.4 is implemented with the following interlinked nine modules:

- Population GDP: Incorporates external projections on population and gross domestic product;

- Car stock: Projects car ownership, resulting aggregate car sales as well as the simulation of the market shares by car technology;

- Travel demand by car: Estimates travel demand by car and energy;

- Infrastructure: Determines the deployment of public refueling and recharging infrastructure;

- Technology choice: Comprises of the model's main behavioral assumptions;

- Production costs: Considers three broad classes of car attributes-technical features, production costs, and consumer costs;

- Energy: Contains energy prices, electricity mix, and energy use; 


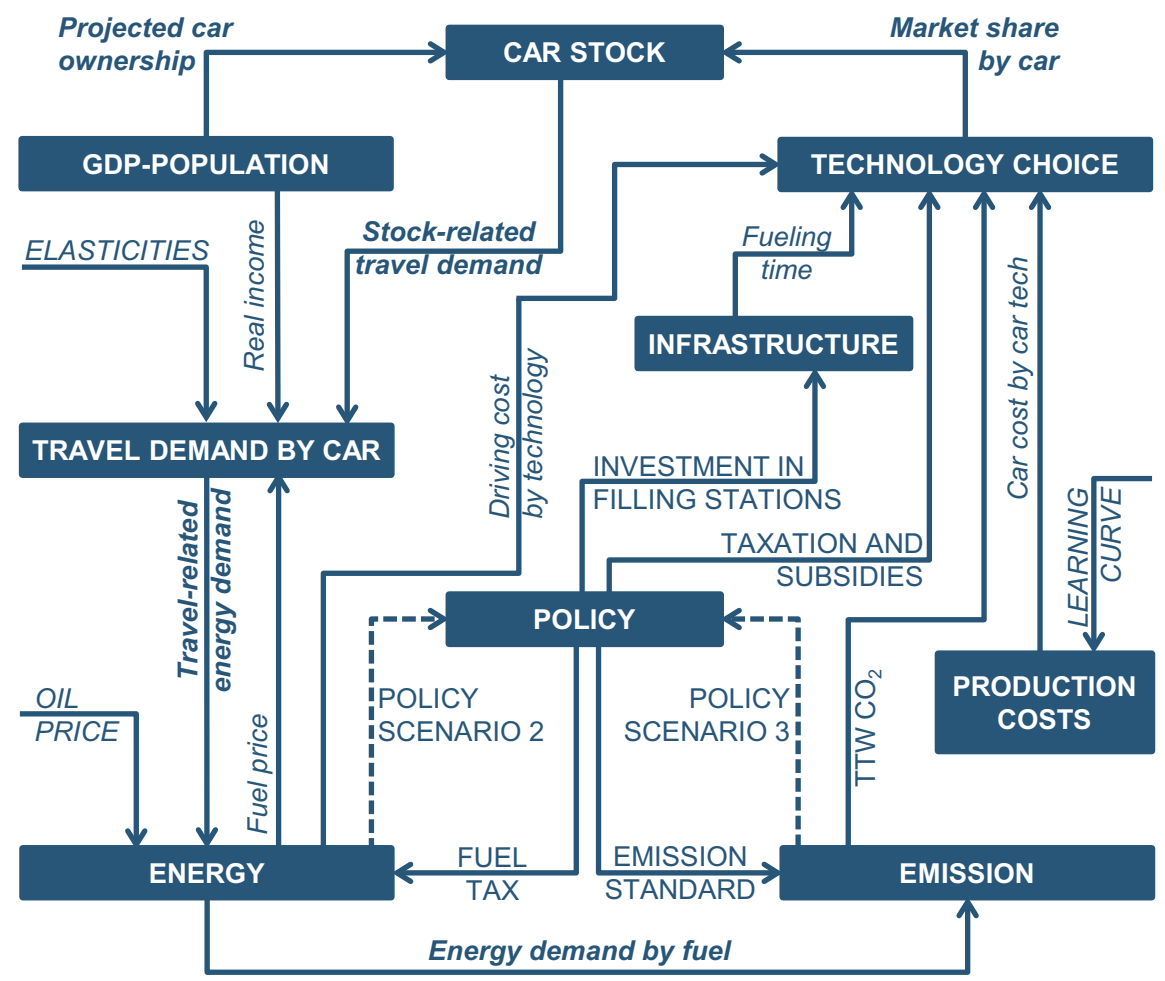

\section{Legend: MODUL NAME / EXOGENOUS / POLICY INPUT / Intermediate input} Intermediate output $\longrightarrow$ (feedback) $\quad--\rightarrow$ (feedforward)

Fig. 3.4 Overview of the TE3 model structure with main linkages between modules. Figure adapted according to Gomez Vilchez et al. (2016)

- Emission: Calculates corresponding GHG emissions divided into six submodules-emission factors, new car emissions, manufacturing and scrappage, tank-to-wheel (TTW), well-to-tank (WTT), and life cycle; and

- Policy: Facilitates policy analysis.

\subsection{8 eLCA and SLCA}

(by Karlsruhe Institute of Technology and KTH Royal Institute of Technology)

Environmental life cycle assessment (eLCA) and social life cycle assessment (sLCA) are two variants based on the general setting of the life cycle assessment (LCA) methodology (ISO 2006). The application of the standardized LCA 
method urges a precise model-based setting of life cycle thinking. Life cycle thinking considers the impacts on the environment or society due to the entire process chain ("cradle to grave") to disclose hotspots affected along the process chain of technology or system under investigation (Heiskanen 2002; Xu et al. 2020).

In the REFLEX project, the main objective was to develop a transparent modelbased setting for environmental and social impact assessment using inputs among others from large energy system models (ESMs) where the changes in energy technologies, supply chains, and systems are accounted for. A more detailed description of the general structure and the coupling of the LCA tools with the ESM is given in Sect. 3.3.

\subsection{9 $\pi E S A$}

(by AGH University of Science and Technology Kraków)

\subsubsection{General Information}

As a platform for an Integrated Energy System Analysis $\pi$ ESA (spoken Pi-ESA) is used to analyze the changes in air quality and human health impacts associated with different energy scenarios. The concept of $\pi$ ESA is based on the DriverPressure-State-Impact-Response (DPSIR) framework. The main element of $\pi \mathrm{ESA}$ is the Polyphemus Air Quality System (Mallet et al. 2007). It employs the Eulerian chemistry-transport-model called Polair3D that enables to track atmospheric dispersion of air pollutants. The spatial domain of $\pi$ ESA can be freely set and mainly depends on the availability of data that are needed to perform simulation runs. In the REFLEX project the modeling domain covers Europe with the geographical extend of $12.0^{\circ} \mathrm{W}, 27^{\circ} \mathrm{E}$ of longitude and $35.0^{\circ} \mathrm{N}-69^{\circ} \mathrm{N}$ of latitude. The horizontal resolution was set to $1.0^{\circ} \mathrm{x} 1.0^{\circ}$ (along longitude and latitude, respectively). Five vertical levels were used with the following limits (in meters above surface): 0, 50, $600,1,200,2,000$, and 3,000. The results of pollutants concentration recorded in the first vertical level i.e., from $0 \mathrm{~m}$ to $50 \mathrm{~m}$ were used to analyze the health impacts. $\pi$ ESA considers only the health impact due to people's long-term exposure to fine particulate $\left(\mathrm{PM}_{2.5}\right)$ air pollution. The main indicator calculated by $\pi \mathrm{ESA}$ is the Loss of Life Expectancy (LLE), which is often used as a proxy for quantifying the overall impact on a population's health. In addition, $\pi$ ESA estimates newly observed cases of Chronic Bronchitis (CB) and the number of days when an individual's routine activities is disrupted due to elevated concentration of $\mathrm{PM}_{2.5}$ i.e., Restricted Activity Days. These impacts are calculated using the, so-called, concentration-response functions (CRFs), which relates the quantity of a pollutant that affects a population (accounting for the absorption of the pollutant from the air into the body) to the physical impact. 


\subsubsection{Model Structure}

The main component of $\pi$ ESA is the Polyphemus Air Quality System, which structure is depicted in Fig. 3.5. It contains the numerical solver Polair3D used for both gaseous and aerosol species. Polair3D tracks multiphase chemistry: (i) gas, (ii) water and (iii) aerosols and has several chemical mechanisms for gaseous pollutants, heavy metals aerosols, radioactive elements, and inert compounds. Polair3D includes the gas-phase chemical mechanism RACM, the Variable Size-Resolution Model VSRM, the Size-resolved Aerosol Model SIREAM and the Aerosol Thermodynamic Model ISORROPIA. Applied chemical schemes allow to model effects of condensation/evaporation coagulation and nucleation upon the particle size distribution. Additionally, Polyphemus includes a library of physical parameterizations called AtmoData and a set of programs using AtmoData designed to generate data required by Polair3D, e.g., deposition velocities, vertical diffusion coefficients, emissions, etc.

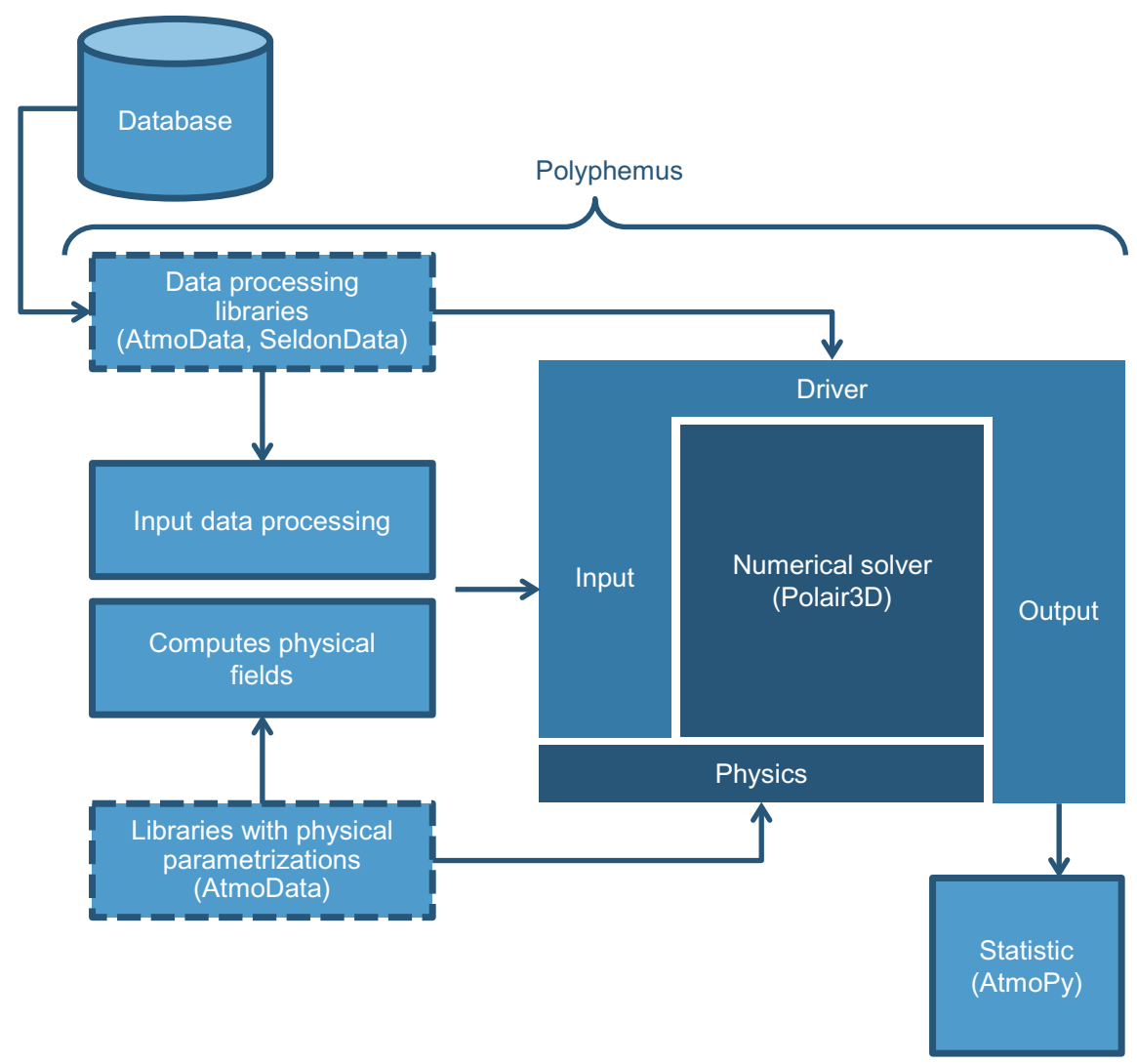

Fig. 3.5 Structure of the Polyphemus Air Quality System—main component of the $\pi$ ESA model (Source Own illustration) 
The calculations are prepared based on the following data among others: anthropogenic and natural emissions (volume and surface), metrological fields (from the European Centre for Medium-Range Weather Forecasts or the Weather Research and Forecasting Model), initial and boundary concentration and land use data.

The approach to estimate the health impacts of air pollution in $\pi$ ESA is based on the methodology developed within a series of the ExternE projects ${ }^{6}$. Health impacts $(I)$ are calculated using the concentration-response functions $(C R F s)$, which in general, have the following formulae:

$$
I=C o n \cdot P o p \cdot F r \cdot C R F
$$

$I$ is the health impact of a given type (e.g., years of life lost-YOLL, reactive airway disease- $R A D$, chronic bronchitis- $C B)$, Con is the concentration of $\mathrm{PM}_{2.5}\left[\mu \mathrm{g} / \mathrm{m}^{3}\right]$, $P o p$ denotes the population exposed, $\mathrm{Fr}$ is the fraction of population affected and $C R F$ is the concentration-response function for a given impact type. $\mathrm{PM}_{2.5}$ impacts have been estimated for the full range of observed concentrations. In the last step $\pi$ ESA estimates the external costs by totalizing the monetary values assigned to respective health impacts.

\subsection{REFLEX Energy Models System}

The specific strengths of the stand-alone models described above are combined in REFLEX for a comprehensive and simultaneously in-depth analysis of the European energy system. Through the model coupling essential exogenous parameters of the individual applications become endogenous variables of the Energy Models System by using relevant output data of one model as input data for another model. In the following the models' interaction within the model-based analysis and the data exchange between the models are described.

To achieve robust results by applying the Energy Models System for each REFLEX scenario, several iterations with the interlinked models have been performed. The calculated intermediate model results were exchanged between the models via a common project database. Figure 3.6 gives an overview about the model coupling and data exchange in REFLEX.

Common scenario framework data and assumptions (e.g., development of population, import fuel prices on EU borders etc.) are harmonized and implemented in the models to provide consistent estimations, before running the Energy Models System. Additionally, initial electricity prices for EU countries are determined.

The following explanations focus exclusively on data exchange between the models. Depending on the focus of analysis, the results of the individual models contain a lot more of additional data and information that are not considered here.

\footnotetext{
${ }^{6}$ For more information see http://www.externe.info/externe_d7/.
} 


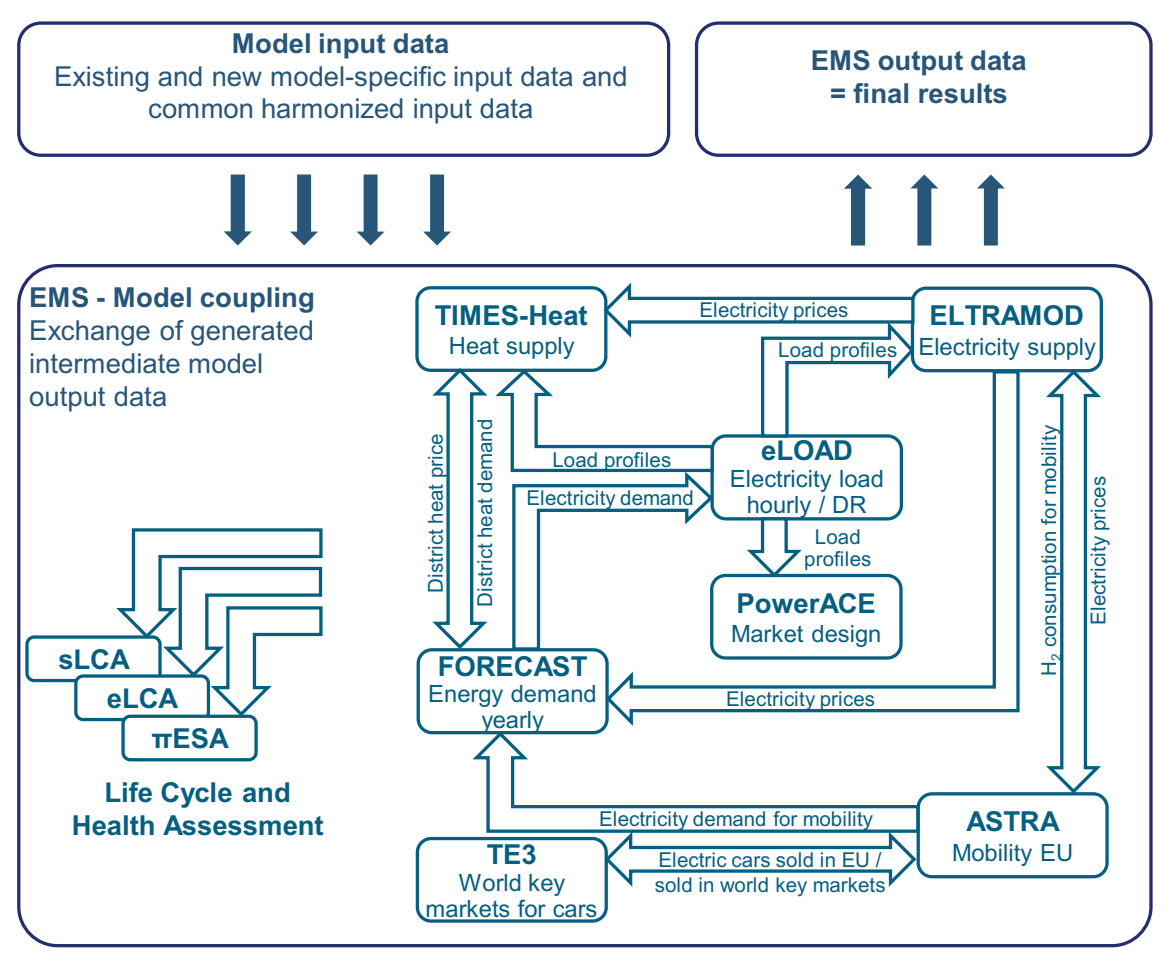

Fig. 3.6 Model coupling and data exchange in the REFLEX project (Source Own illustration)

As a first step, the ASTRA model determines the energy demand for mobility in Europe, considering the development of different transport technologies. In order to estimate the market penetration of electric vehicles and the associated global cost effects (future prices of electric vehicle batteries and fuel cells based on the learning curve theory), the development of the road passenger sectors for non-EU key markets is simulated with the TE3 model. In this sense, the global automotive market (especially including Northern America and Asia) is considered for investigating the uptake of alternative car technology in Europe (cf. Heitel et al. 2019). After some iterations between the models to stabilize the results, the electricity demand for mobility calculated by ASTRA is provided to FORECAST with a yearly resolution.

Afterwards, by considering the results of ASTRA for the transport sector, FORECAST performs a projection of the development and annual consumption of all relevant energy carrier for the remaining energy consuming sectors (industry, tertiary and residential sector).

In the next step, the annual electricity demand calculated by FORECAST is provided to the eLOAD model. Within eLOAD, the hourly resolution of electricity demand is modeled while demand response measures are considered. Therefore, specific load curves are used for about 50 different processes and energy applications that vary during a day or week. 
The eLOAD model passes the results of hourly electricity demand to ELTRAMOD. In addition, the yearly hydrogen consumption in the mobility sector is provided from ASTRA. ELTRAMOD calculates the optimal investment and concerning additional power plant capacities, storage facilities and power-to-X capacities (e.g., electrolyzers). Furthermore, the optimal dispatch decision of these plants and units is estimated by fulfilling the electricity demand in each hour of a year as well as the yearly hydrogen and heat demand by minimizing the total system costs. The exchange of electricity between EU countries is modeled endogenously and restricted by given net transfer capacities. The calculation of new investments in power plant capacities and electricity price developments are the main results of ELTRAMOD.

While ELTRAMOD focuses on the electricity supply, TIMES-Heat-EU analyzes the heat system in parallel. Both sectors are mainly connected through CHP plants and electric powered heating units, which are considered in TIMES-Heat-EU. Input parameter for TIMES-Heat-EU are ELTRAMOD results such as the annual capacities and hourly operation of all power plants without CHP as well as RES curtailment and the electricity prices. Additionally, TIMES-Heat-EU receives the projection of the annual district heat demand from FORECAST. Thereafter, TIMES-Heat-EU estimates the development of the heat system and determines a projection for the district heat prices, which are returned to FORECAST in preparation for the next iteration loop of the EMS. The results of ASTRA, FORECAST, and ELOAD are highly dependent on the electricity price development provided by ELTRAMOD. Once the models receive the wholesale electricity prices, the next iteration of the EMS can be initialized.

In addition to ELTRAMOD, PowerACE simulates the electricity supply-side too, but focuses more on the analysis of the impact concerning different electricity market designs on investments in flexibility options and security of supply with an agent-based approach. Therefore, as a final step after finalizing the iterations for one scenario, the hourly electricity demand from eLOAD is provided to the PowerACE model. All relevant parameters of the electricity sectors are harmonized between ELTRAMOD and PowerACE (e.g., NTCs, generation efficiency, initial power plant capacities, and decommissioned capacities by power plant age etc.). Beyond that, the models TIMES-Heat-EU, ELTRAMOD and PowerACE deliver input data on installed power plant capacity, energy demand of power plants, operation and electricity generation as well as emissions by country. From the ASTRA model data are provided at country level in terms of energy usage, vehicle stock, employment, and car ownership.

Finally, the LCA tools assess the impacts on environment and society of the projected pathways of the energy system. Therefore, the tools require data describing consumables in the energy systems (i.e., fuels, renewable and non-renewable) as well as capital for each sector of the energy system. FORECAST provides the LCA-based assessment tools with data on final energy demand disaggregated with respect to the energy carrier.

Figure 3.7 illustrates the background framework for coupling the LCA (both eLCA and sLCA) and ESMs of the REFLEX project following the principles of EAFESA, 


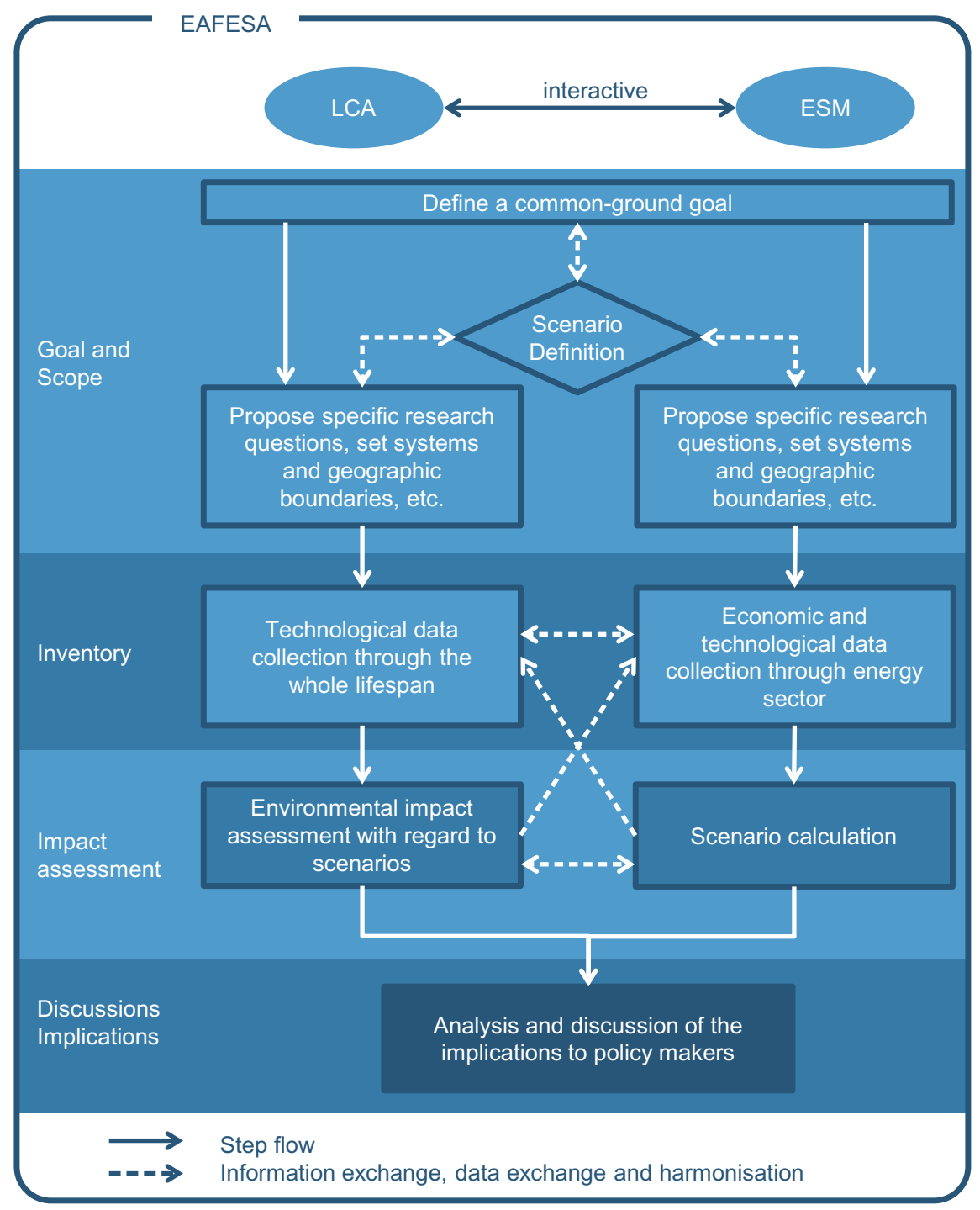

Fig. 3.7 Overview of Environmental Assessment Framework for Energy System Analysis (EAFESA). Figure adapted according to Xu et al. (2020)

Environmental Assessment Framework for Energy System Analysis (Xu et al. 2020). EAFESA guarantees transparency and robustness of the information exchanged and harmonized between the ESMs and LCA. In this regard, EAFESA consists of four steps structured according to the LCA methodology (ISO 2006).

Firstly, EAFESA requests to define a common-ground goal based on the map of technologies considered in the ESMs and LCA. If necessary, technologies need 
to be disaggregated to merge the system boundaries and scope of ESMs and LCA model-based settings. Secondly, the inventory analysis demands categorizing the needed set of harmonized data for both approaches and, as a follow-up, making the harmonization of the data. The overarching criteria to justify any change in data for emerging technologies is that it should be consistent in light of the overarching scenario that is considered. This step differs between the eLCA and sLCA because of the scope and databases. Thirdly, impact assessment should enable assessment of the societal objectives identified in the objective definition from a social and environmental perspective. In this step, the outcome of each model-based setting is discussed between the ESMs and LCA. The discussion and implication provide two distinct roles. Firstly, life cycle processes that make a significant beneficial contribution to each social and environmental impact category shall be identified. Secondly, unintended environmental and social burdens (cf. PART V Chapters 13 and 14) that should require government attention are identified and discussed.

\section{References}

EC (2016) EU energy trends and macroeconomic performance. D1 study on the macroeconomics of energy and climate policies. European commission, Directorate-General for Energy, Contract no. ENER/A4/2015-436/SER/S12.716128

EC (2018) A technical analysis on decarbonisation scenarios-constraints, economic implications and policies. Technical study on the macroeconomics of energy and climate policies. European Commission, Directorate-General for Energy, Contract no. ENER/A4/2015436/SER/S12.716128

Keramidas K, Diaz Vazquez A, Weitzel M, Vandyck T, Tamba M, Tchung-Ming S, Soria Ramirez A, Krause J, Van Dingenen R, Chai Q, Fu S, Wen X (2020) Global energy and climate outlook 2019: electrification for the low-carbon transition, Publications Office of the European Union, Luxembourg. https://doi.org/10.2760/35080

Elsland R (2016) Long-term energy demand in the German residential sector-de-velopment of an integrated modeling concept to capturetechnological myopia. Karlsruhe Institute for Technology, Baden-Baden, NOMOS

Fleiter T, Rehfeldt M, Herbst A, Elsland R, Klingler A-L, Manz P, Eidelloth S (2018) A methodology for bottom-up modelling of energy transitions in the industry sector: The FORECAST model. Energy Strat Rev 22:237-254

Fraunhofer ISI, IREES, TEP Energy (2017) FORECAST/eLOAD website. https://forecast-mod el.eu. Accessed on 29 Jun 2017

Fraunholz C, Keles D (2019) D5.2 report on investments in flexibility options considering different market designs. REFLEX project report

Fraunholz C, Keles D, Fichtner W (2019) Agent-based generation and storage expansion planning in interconnected electricity Markets. In: 2019 16th international conference on the European Energy Market (EEM)

Gnann T, Klingler A-L, Kühnbach M (2018) The load shift potential of plug-in electric vehicles with different amounts of charging infrastructure. J Power Sources 390(30):20-29. https://doi. org/10.1016/j.jpowsour.2018.04.029

Gomez Vilchez J, Jochem P, Fichtner W (2016) Car technology market evolution and emissions impacts - an example of energy policy scenarios under uncertainty external link. Proceedings of the 34th International Conference of the System Dynamics Society Cambridge, Delft, July $17-21,1-15$ 
Heiskanen E (2002) The institutional logic of life cycle thinking. J Clean Prod 10(5):427-437. https://doi.org/10.1016/S0959-6526(02)00014-8

Heitel S, Seddig K, Gómez Vilchez JJ, Jochem P (2019) Global electric car market deployment considering endogenous battery price development. In: Louwen A, Junginger M (eds) Technological learning in the transition to a low carbon energy system. Elsevier. https://doi.org/10.1016/ B978-0-12-818762-3.00015-7

ISO (2006) Environmental management-life cycle Assessment-principles and framework. International Organization for Standardization (ISO), Switzerland

Jakob M, Fleiter T, Catenazzi G, Hirzel S, Reitze F, Toro F (2012) The impact of policy measures on the electricity demand of the tertiary sector of the European Union: An analysis with the bottom-up model FORECAST, conference proceedings of IEECB 18-19, April, Frankfurt

Keles D, Bublitz A, Zimmermann F, Genoese M, Fichtner W (2016) Analysis of design options for the electricity market: the German case. Appl Energy 183:884-901. https://doi.org/10.1016/ j.apenergy.2016.08.189

Ladwig T (2018) Demand side management in Deutschland zur Systemintegration erneuerbarer Energien. Dissertation. Technische Universität Dresden, Dresden. http://nbn-resolving.de/urn: nbn:de:bsz:14-qucosa-236074

Loulou R (2008) ETSAP-TIAM: the TIMES integrated assessment model. Part II: mathematical formulation. CMS 5:41-66. https://doi.org/10.1007/s10287-007-0045-0

Mallet V, Quello D, Sportisse B, Ahmed de Biasi M, Debry E, Korsakissok I, Wu L, Roustan Y, Sartelet K, Tombette M, Foudhil H (2007) Technical note: the air quality modeling system polyphemus. Atmos Chem Phys 7(20):5479-5487. https://doi.org/10.5194/acp-7-5479-200

Martino A, Fermi F, Astegiano P (2018) Investigating the impact of e-bikes on modal share and greenhouse emissions: a system dynamic approach. 21st EURO working group on transportation meeting (EWGT), Braunschweig, September 17-19

Martino A, Fermi F, Heitel S, Krail M (2019) EU transport sector decarbonisation: simulating the impacts of the diffusion of electric vehicles with the ASTRA SD model. 2nd annual workshop on system dynamics in transportation modelling, institute of transport studies, University of Leeds, April 11-12

Ringler P, Keles D, Fichtner W (2017) How to benefit from a common European electricity market design. Energy Policy 101:629-643. https://doi.org/10.1016/j.enpol.2016.11.011

Schubert DKJ (2016) Bewertung von Szenarien für Energiesysteme: Potenziale, Grenzen und Akzeptanz. Dissertation. Technische Universität Dresden, Dresden. https://nbn-resolving.org/ urn:nbn:de:bsz:14-qucosa-202226

Schreiber S, Zöphel C, Fraunholz C, Reiter U, Herbst A, Fleiter T, Möst D (2020) Experience curves in energy models-lessons learned from the REFLEX project. In: Louwen A, Junginger M (eds) Technological learning in the transition to a low Carbon energy system. Elsevier. https://doi.org/ 10.1016/B978-0-12-818762-3.00014-5

Xu L, Fuss M, Poganietz WR, Jochem P, Schreiber S, Zöphel C, Brown N (2020) An environmental assessment framework for energy system analysis (EAFESA): the method and its application to the European energy system transformation. J Clean Prod 243 (10):118614. https://doi.org/10. 1016/j.jclepro.2019.118614

Zöphel C, Schreiber S, Herbst A, Klingler AL, Manz P, Heitel S, Fermi F, Wyrwa A, Raczyński M, Reiter U, Möst D (2019) Report on cost optimal energy technology portfolios for system flexibility in the sectors heat, electricity and mobility. REFLEX project report 
Open Access This chapter is licensed under the terms of the Creative Commons Attribution 4.0 International License (http://creativecommons.org/licenses/by/4.0/), which permits use, sharing, adaptation, distribution and reproduction in any medium or format, as long as you give appropriate credit to the original author(s) and the source, provide a link to the Creative Commons license and indicate if changes were made.

The images or other third party material in this chapter are included in the chapter's Creative Commons license, unless indicated otherwise in a credit line to the material. If material is not included in the chapter's Creative Commons license and your intended use is not permitted by statutory regulation or exceeds the permitted use, you will need to obtain permission directly from the copyright holder.

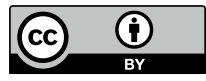

